\title{
Influence of infarct artery patency on the relation between initial ST segment elevation and final infarct size
}

\author{
ROSEMARY A HACKWORTHY, MICHAEL B VOGEL, PHILLIP J HARRIS \\ From the Hallstrom Institute of Cardiology, Royal Prince Alfred Hospital, Camperdown, New South Wales, \\ Australia
}

SUMMARY Thirty seven patients with acute myocardial infarction were studied to determine the effect of perfusion of the infarct artery on the relation between the extent of initial ST segment elevation and final electrocardiographic infarct size. The sum of the initial peak ST elevations in all leads correlated with electrocardiographic infarct size in patients with anterior infarction and total occlusion of the infarct artery without collaterals. In patients with anterior infarction and subtotal occlusion of the infarct artery and in all patients with inferior infarction, infarct size was smaller than predicted from the extent of initial ST segment elevation. Collaterals to the infarct artery were present in eight of the 10 patients with inferior infarction and total occlusion. In patients with a persistently occluded infarct artery without collaterals the final infarct size correlated with the extent of initial peak ST segment elevation.

This study provides further evidence that spontaneous reperfusion by anterograde flow or via collaterals may salvage jeopardised myocardium.

In dogs early epicardial ST segment elevation after coronary occlusion reflects the extent of jeopardised myocardium ${ }^{1}$ and is closely related to final infarct size. ${ }^{12}$ Although the extent of early ST segment elevation has been used as a measure of final infarct size in patients with acute myocardial infarction, ${ }^{3-5}$ the relation is less precise than it is in dogs..$^{6-8}$ One explanation for the variation in this relation in man is that spontaneous reperfusion of the infarct artery by recanalisation or the early development of collateral channels leads to preservation of jeopardised myocardium. ${ }^{9-11}$

Spontaneous recanalisation occurs in up to $13 \%$ of patients within four hours of the onset of symptoms of infarction and in about $35 \%$ of patients by 12 to 24 hours. ${ }^{12}$ Collaterals develop in about $16 \%$ of patients within six hours of infarction and in about $62 \%$ of patients by two weeks. ${ }^{13}$

Requests for reprints to Dr Phillip J Harris, Hallstrom Institute of Cardiology, Royal Prince Alfred Hospital, Camperdown, NSW 2050, Australia.

Accepted for publication 28 April 1986
The aim of this study was to determine whether patency of the infarct artery, established at angiography before discharge, was a factor in the relation between initial ST segment elevation and final electrocardiographic infarct size in patients with acute myocardial infarction.

\section{Patients and methods}

\section{PATIENTS}

The study population consisted of 37 patients (34 men and three women) who were admitted to hospital within six hours of the onset of symptoms of acute myocardial infarction and who had ST segment elevation of $1 \mathrm{~mm}$ or more in two or more leads on a 12 lead electrocardiogram. The mean age of the patients was 53 (31-64) years. Eighteen patients had anterior, 17 had inferior, and two had lateral infarction. All patients were managed in the coronary care unit and received intravenous lignocaine for the first $\mathbf{4 8}$ hours. Nitrates were given if required for recurrence of ischaemic chest pain, and two patients received intravenous $\beta$ blocker treatment. 
ELECTROCARDIOGRAPHIC MEASUREMENTS

A 12 lead electrocardiogram was performed immediately after presentation of the patient to the emergency centre and on arrival in the coronary care unit. To measure early peak segment ST elevation electrocardiograms were repeated every 1-2 hours until eight hours after the onset of symptoms of infarction. All electrocardiograms were digitised by a single observer using a digitiser interfaced with a computer system. ST segment elevation was measured $0.04 \mathrm{~s}$ after the end of the QRS complex. $\Sigma S T$, the sum of ST segment elevation in all leads, was calculated in $\mathrm{mV}$; ST segment depression was not measured.

All patients had a 12 lead electrocardiogram before discharge from hospital (mean (SD)) (day 9 (2)) that was digitised to measure the sum of $Q$ waves ( $\Sigma Q$ ), a $Q R S$ score based on $Q$ and $R$ wave duration and amplitude, and $R: Q$ and $R: S$ amplitude ratios. ${ }^{14} \mathrm{~A} Q \mathrm{QRS}$ score of three or more has a $98 \%$ specificity for infarction.

\section{CORONARY ANGIOGRAPHY}

Selective coronary angiography was performed in multiple projections before discharge from hospital (day 11 (4)) in 33 patients, and within eight weeks of discharge in the remaining four patients. ${ }^{15}$ The infarct artery was defined as being totally or subtotally occluded. A totally occluded infarct artery had no or very poor anterograde flow beyond a complete obstruction-equivalent to grade 0 or 1 perfusion in the thrombolysis in myocardial infarction (TIMI) trial. ${ }^{16}$ A subtotally occluded artery was defined as one that had brisk anterograde flow beyond a partial obstruction-equivalent to grade 2 or 3 in the TIMI trial. ${ }^{16}$ Patients with total occlusion were defined as having collateral flow to the infarct artery if the distal vessel filled retrogradely via collaterals early after injection of contrast. $^{17}$

\section{STATISTICAL ANALYSIS}

The relation between initial peak ST segment elevation and the electrocardiographic measurements of infarct size at discharge was tested by regression analysis and Student's unpaired $t$ test. A probability (p) of $<0.05$ was considered to be significant.

Table Correlation coefficients for relation between peak initial $\Sigma S T$ and infarct size at discharge

\begin{tabular}{llll}
\hline & $r$ & $S E E$ & $p$ \\
\hline Discharge QRS score & 0.48 & 3.33 & $<0.01$ \\
Discharge $\Sigma Q$ & 0.42 & 2.51 & $<0.01$ \\
\hline
\end{tabular}

r, correlation coefficient; SEE, standard error of the estimate.

\section{Results}

In the total group of 37 patients there was a poor correlation between peak initial $\Sigma S T$ and final electrocardiographic infarct size measured by the QRS score and $\Sigma Q$ (table). The correlation was not improved by considering patients with anterior and inferior infarction separately.

At predischarge coronary angiography seven of the 18 patients with anterior infarction and 10 of the 17 patients with inferior infarction had total occlusion of the infarct artery. Collateral supply to the distal infarct artery was not present in any of the seven patients with anterior infarction and total occlusion, but was present in eight of the 10 patients with inferior infarction and total occlusion.

The figure shows the effect of patency of the infarct artery on the relation between peak initial

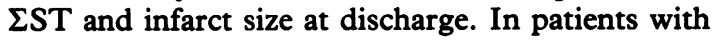
anterior infarction and total occlusion of the infarct artery there was a close correlation between peak initial $\Sigma$ ST and each of the two indices of infarct size ( $r=0.78$ for QRS score, and $r=0.91$ for $\Sigma Q$ ).

In patients with anterior infarction and subtotal occlusion of the infarct artery there was a very poor correlation between $\Sigma S T$ and final infarct size. Approximately half of these patients, however, had a similar relation to that in the patients with total
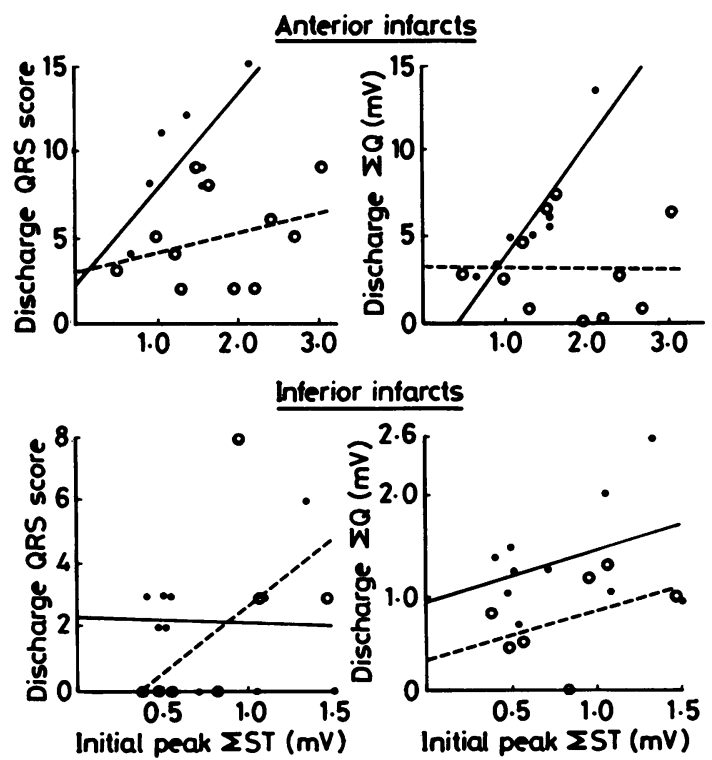

Figure Relation between initial peak $\Sigma S T$ and infarct size at discharge ( $Q R S$ score and $\Sigma Q$ ) in patients with anterior and inferior infarcts and with total or subtotal occlusion. Closed circles and solid lines indicate total occlusion. Open circles and dashed lines indicate subtotal occlusion. 
occlusion, whereas the remainder fell well below the line of identity. Among patients with inferior infarction there was a poor correlation between peak initial $\Sigma S T$ and both QRS score and $\Sigma Q$ regardless of whether the infarct artery was totally or subtotally occluded.

The ratio of QRS score at discharge to peak initial $\Sigma S T$ is a possible measure of the relation between the initial amount of jeopardised myocardium and the final infarct size. This ratio (SD) was higher in the anterior infarct patients with total occlusion than in the anterior infarct patients with subtotal occlusion $(7.49(1.93)$ vs $3.31(1.94), \mathrm{p}<0.001)$. There was no significant difference in this ratio between patients with inferior infarction and total or subtotal occlusion $(3.41(2.66)$ vs $1.88(3.07)$, $\mathrm{p}=\mathrm{NS}$ ).

\section{Discussion}

There was a close correlation between the extent of early ST segment elevation and electrocardiographic infarct size at discharge in patients with anterior infarction and persistent total occlusion of the infarct artery without collaterals. This relation had a standard error of the estimate of 2 points, which is approximately equivalent to $7 \%$ of left ventricular mass. ${ }^{18}$ Approximately half the patients with anterior infarction and subtotal occlusion had the same final infarct size relative to the degree of initial ST segment elevation as the patients with total occlusion, but the remainder had a significantly smaller final infarct size.

There was no correlation between final infarct size and early ST segment elevation in patients with inferior infarction regardless of whether or not they had total or subtotal occlusion of the infarct artery. The frequency of collaterals was much higher in patients with inferior infarction and total occlusion than in patients with anterior infarction and total occlusion.

Askenazi $e t a l^{3}$ and other workers ${ }^{45}$ found a good correlation between the early peak $\Sigma S T$ and final infarct size in patients with myocardial infarction. Norris et al, Thompson et al, and Zmyslinski et al, using similar methods did not find a correlation between these variables. ${ }^{6-8}$ These studies did not consider patency of the infarct artery, and the variation between the reports may have been due to the inclusion of different proportions of patients with occluded and patent arteries.

Leiboff et al and Rogers et al have shown that among patients receiving intracoronary streptokinase those with early anterograde or retrograde perfusion of the infarct artery have better left ventricular function than patients with early total occlusion without collaterals. ${ }^{910}$ The strongest evidence that spontaneous recanalisation may preserve myocardium comes from Ong et al who found improved left ventricular function in patients with indirect evidence of spontaneous reperfusion. ${ }^{11}$

In our study there appeared to be two subpopulations of patients with anterior infarction and subtotal occlusion, those with the same relation between initial ST segment elevation and final infarct size as the patients with total occlusion, and those with a smaller infarct size in relation to initial ST segment elevation. Reduction of infarct size by reperfusion in animals is critically dependent on the delay to reperfusion. ${ }^{1920}$ One explanation for the variation in the relation among patients with subtotal occlusion is that spontaneous reperfusion occurred at a variable time and that in some patients it was early enough to preserve myocardium. In those in whom it was not the initial $\Sigma S T$ to final infarction size relation was the same as it was in patients with total occlusion.

In patients with inferior infarction the relation between initial ST segment elevation and final infarct size was variable. At predischarge angiography, however, eight of the 10 patients with inferior infarction and total occlusion had collaterals supplying the distal infarct artery and it was therefore not possible to compare the relations in patients with perfused and unperfused infarct arteries.

This study suggests that the extent of early ST segment elevation in patients with anterior infarction can be used to select patients for immediate intervention because it identifies the amount of myocardium at risk if the artery were to stay totally occluded. Further, the relation of extent of ST segment elevation to final infarct size may be an important index of the success of thrombolytic interventions in such patients.

This study was supported by a postgraduate medical research scholarship from the National Heart Foundation, Canberra, Australia.

\section{References}

1 Muller JE, Maroko PR, Braunwald E. Precordial electrocardiographic mapping. A technique to assess the efficacy of interventions designed to limit infarct size. Circulation 1978;57:1-18.

2 Hillis LD, Askenazi J, Braunwald E, et al. Use of changes in the epicardial QRS complex to assess interventions which modify the extent of myocardial necrosis following coronary artery occlusion. Circulation 1976;54:591-8.

3 Askenazi J, Maroko PR, Lesch M, Braunwald E. Usefulness of ST segment elevations as predictors of 
electrocardiographic signs of necrosis in patients with acute myocardial infarction. $\mathrm{Br}$ Heart $\boldsymbol{f}$ 1977;39:764-70.

4 Yusuf S, Lopez R, Maddison A, et al. Value of electrocardiogram in predicting and estimating infarct size in man. Br Heart $\mathcal{f}$ 1979;42:286-93.

5 Henning H, Hardarson T, Francis G, O'Rourke RA, Ryan W, Ross J. Approach to the estimation of myocardial infarct size by analysis of precordial $\mathrm{S}-\mathrm{T}$ segment and $\mathrm{R}$ wave maps. Am $\mathcal{f}$ Cardiol 1978;41:1-8.

6 Norris RM, Barratt-Boyes C, Heng MK, Singh BN. Failure of ST segment elevation to predict severity of acute myocardial infarction. $\mathrm{Br}$ Heart $\mathcal{F}$ 1976;38: 85-92.

7 Thompson PL, Katavatis V. Acute myocardial infarction. Evaluation of praecordial ST segment mapping. Br Heart $\mathcal{f}$ 1976;38:1020-4.

8 Zmyslinski RW, Akiyama T, Biddle TL, Shah PM. Natural course of the S-T segment and QRS complex in patients with acute anterior myocardial infarction. Am $\mathcal{F}$ Cardiol 1979;43:29-34.

9 Leiboff RH, Katz RJ, Wasserman AG, et al. A randomized, angiographically controlled trial of intracoronary streptokinase in acute myocardial infarction. Am $\mathcal{f}$ Cardiol 1984;53:404-7.

10 Rogers WJ, Hood WP, Mantle JA, et al. Return of left ventricular function after reperfusion in patients with myocardial infarction: importance of subtotal stenoses or intact collaterals. Circulation 1984;69: 338-49.

11 Ong L, Reiser P, Coromilas J, Scherr L, Morrison J. Left ventricular function and rapid release of creatine kinase $\mathrm{MB}$ in acute myocardial infarction. Evidence for spontaneous reperfusion. $N$ Engl $\mathcal{F}$ Med 1983; 309:1-6.
12 de Wood MA, Spores J, Notske R, et al. Prevalence of total coronary occlusion during the early hours of transmural myocardial infarction. $N$ Engl $\mathcal{F}$ Med 1980;303:897-902.

13 Schwartz H, Leiboff RH, Bren GB, et al. Temporal evolution of the human coronary collateral circulation after myocardial infarction. $\mathcal{F} \mathrm{Am}$ Coll Cardiol 1984;4:1088-93.

14 Wagner GS, Freye CJ, Palmeri ST, et al. Evaluation of a QRS scoring system for estimating myocardial infarct size: I. Specificity and observer agreement. Circulation 1982;65:342-7.

15 Roubin GS, Shen WF, Nicholson M, Dunn RF, Kelly DT, Harris PJ. Anterolateral ST segment depression in acute inferior myocardial infarction: angiographic and clinical implications. Am Heart $\mathcal{f} 1984 ; 107$ : $1177-82$.

16 The TIMI study group. The thrombolysis in myocardial infarction (TIMI) trial. Phase I findings. N Engl f Med 1985;312:932-6.

17 Hecht HS, Areosty JM, Morkin E, LaRaia PJ, Paulin S. Role of the coronary collateral circulation in the preservation of left ventricular function. Diagn Radiol 1975;114:305-13.

18 Ideker RE, Wagner GS, Ruth WK, et al. Evaluation of a QRS scoring system for estimating myocardial infarct size. II. Correlation with quantitative anatomic findings for anterior infarcts. Am $\mathrm{f}$ Cardiol 1982;49:1604-14.

19 Mathur VS, Guinn GA, Burris WH. Maximal revascularization (reperfusion) in intact conscious dogs after 2 to 5 hours of coronary occlusion. $A m \mathcal{F}$ Cardiol 1975;36:252-61.

20 Bolooki H, Kotler MD, Lottenberg L, et al. Myocardial revascularization after acute infarction. $A m \mathcal{F}$ Cardiol 1975;36:395-406. 